\title{
Persona satírica e mudança de tom na obra juvenaliana ${ }^{1}$
}

\author{
Iana Lima Cordeiro \\ Leni Ribeiro Leite ${ }^{3}$
}

\begin{abstract}
Resumo: Neste artigo trazemos um panorama simplificado de duas perspectivas centrais que se apresentam no estudo contemporâneo das Sátiras do poeta romano Juvenal: a aplicação do conceito de persona poética e a interpretação da suposta mudança de tom que existe em sua obra, composta por 16 sátiras. Discutimos em que medida a postura adotada pelos críticos juvenalianos diante dessas questões ditou sua análise dos poemas e apresentamos nosso próprio posicionamento teórico: concordamos com o uso do conceito de persona e defendemos que a obra juvenaliana não apresenta o que se possa definir como mudança de tom, haja vista que consideramos que uma única persona se mantém ao longo de toda a obra.
\end{abstract}

Palavras-chave: Juvenal. Sátira romana. Crítica biográfica. Persona poética.

\begin{abstract}
We present an overview of the two main perspectives in studying the Satires of the Roman poet Juvenal: the concept of a poetic persona and the apparent change of tone in the course of his 16 poems. We discuss how the scholars' theoretical stance upon these matters have impacted their interpretation of Juvenal's work and we defend our own: we agree with the existence of a poetic persona and disagree with an alleged change of tone, as we sustain there is only one persona throughout the Satires.
\end{abstract}

Keywords: Juvenal. Roman Satire. Biographical Criticism. Poetic Persona.

\section{Introdução}

Há duas questões centrais nos estudos contemporâneos sobre as sátiras juvenalianas: a acepção ou não do conceito de persona poética e a suposta mudança de tom observável ao longo da obra. O posicionamento dos estudiosos de Juvenal diante de ambas as discussões foi determinante para a pluralidade de análises que encontramos hoje das sátiras. Trazemos neste artigo um panorama simplificado dos principais pontos que concernem a essas questões, de modo que possamos discutir suas consequências para o estudo das Sátiras e apresentar nosso próprio posicionamento.

1 Este artigo foi realizado a partir de nossa dissertação de mestrado (CORDEIRO, 2019).

2 Doutoranda do Programa de Pós-Graduação em Letras da Universidade Federal do Espírito Santo (UFES). Projeto de pesquisa: "O vitupério e as práticas invectivas na literatura romana".

3 Doutora em Letras Clássicas. Docente do PPG de Letras e do PPG de História da Universidade Federal do Espírito Santo (UFES). Projeto de pesquisa: "Poéticas do epidítico na era dos imperadores flavianos". 


\section{A falácia biográfica}

Embora estime-se que o poeta satírico Décimo Júnio Juvenal tenha vivido por volta do século II a.C., tratar de sua biografia é uma tarefa complexa. Isso se deve ao fato de que todas as fontes biográficas sobre o poeta a que temos acesso hoje podem ser, em alguma medida, questionadas e mesmo descreditadas. Segundo Braund (2004, p. 18) e Harrington (2009, p. 1), não podemos afirmar seguramente nem que Juvenal tenha sido de fato seu nome. As supostas informações sobre sua vida podem ser encontradas em quatro fontes, como elenca Armstrong (2012, p. 59): a) notas e escólios em biografias de Juvenal escritas durante a Antiguidade tardia; b) referências a si mesmo feitas pelo poeta em seu próprio texto; c) menções a Juvenal em três epigramas de Marcial e d) uma inscrição com o nome de Júnio Juvenal. Todas as fontes elencadas, no entanto, baseiam-se, em alguma medida, em textos poéticos que, enquanto produtos de um trabalho artístico, não têm obrigação de correspondência exata com a realidade empírica, o que põe em xeque a legitimidade de todos esses dados que têm baseado constatações sobre a vida do poeta Juvenal, como veremos.

O problema com as notas e escólios em biografias e as autorreferências de Juvenal em sua obra é que essas duas fontes dão ao texto literário certa credibilidade factual, como se as informações contidas nas sátiras pudessem ser tomadas como indicativos de quem de fato fosse Juvenal ou do que ele tenha feito durante sua vida, para além de escrever poemas. Precisamos ter em mente, ao lidar com esses textos, que muitos de seus aspectos, como o metro utilizado ou a temática escolhida, podem ser antes um atendimento ao decoro do gênero do que uma escolha pessoal do autor que possa ser justificada por sua biografia. Desta forma, não necessariamente aquilo que Juvenal afirma sobre si mesmo ou sobre o mundo representa sua autêntica opinião. Como exemplo de atendimento ao decoro, há a menção ao satirista Lucílio na primeira sátira - também chamada de sátira programática - de Juvenal (1.1.20), aspecto que pode ser considerado parte de uma tradição, pois Lucílio é mencionado também em Horácio (1.10.48) e Pérsio (1.1.114), satiristas antecessores. Um outro ponto em comum entre Juvenal e seus precursores é minorar a importância do próprio gênero que escrevem: Horácio afirma recear recitar seus versos, que ninguém lê (1.4.21-25) ${ }^{4}$, Pérsio declara a escassez de seu público ao afirmar que ou duas pessoas ou ninguém lerá seus versos (1.1.2-3) e Juvenal nega seu dom para a escrita, afirmando partir da indignação, e não do talento, para produzir seus poemas (1.1.9) Não podemos, portanto, tratar do texto juvenaliano sem colocá-lo em perspectiva com os outros textos que fazem parte do mesmo gênero no qual ele se insere: a sátira romana.

A terceira fonte elencada por Armstrong são os epigramas de Marcial que fazem menção a Juvenal: 7.24, 7.91, 12.18. Embora Braund (2004, p. 18) afirme não ser possível ter

4 (...) beatus Fannius ultro/delatis capsis et imagine, cum mea nemo/ scripta legat, volgo recitare timentis ob hanc rem,/ quod sunt quos genus hoc minime iuvat, ut pote pluri/ culpari dignos (...). Tradução de António Luís Seabra: “' (...) Às livrarias/ Leve Fânio, feliz com glória tanta,/ Sem que o roguem, seus versos e retrato:/ Os meus ninguém os lê, e até receio/ Recitá-los em público, que raros/ Ao motejo, à censura inacessíveis,/ Podem recreio achar em tais escritos."

5 'Quis leget haec?' min tu istud ais? nemo hercule. 'Nemo?'/ vel duo vel nemo (...). Tradução de Marihá Barbosa e Castro: “'Quem lerá isto?'. Tu dizes isto para mim? Por Hércules, ninguém! 'Ninguém?'/ Ou dois, ou ninguém."

6 Si natura negat, facit indignatio versum. Tradução de Rafael Cavalcanti do Carmo: Se a natureza recusa-se, a raiva elabora o poema. 
certeza de que Juvenal tenha sido o nome verdadeiro do satirista, a autora não parece se opor à relação entre o Juvenal dos epigramas de Marcial e o autor das Sátiras. A estudiosa, inclusive, ao comentar a opinião de Marcial em um dos epigramas, em que Juvenal é descrito como eloquente ${ }^{7}$, concorda com esse suposto atributo do satirista e justifica que suas sátiras refletem o treinamento retórico recebido por membros da elite romana (BRAUND, 2004, p. 19). As menções presentes na obra, no entanto, não adicionaram muito às informações biográficas sobre Juvenal, pois os poemas que citam o poeta não o têm como objeto, logo não o descrevem nem indicam outros aspectos de sua vida. De todo modo, ainda que fosse possível acessar dados sobre Juvenal a partir dos poemas de Marcial, essas informações seriam questionáveis pelos mesmos motivos que impedem que os poemas do próprio Juvenal sejam fontes confiáveis sobre a vida de seu autor.

Por fim, a última fonte elencada por Armstrong é uma inscrição com o nome de Júnio Juvenal, localizada em um templo dedicado a Ceres na região de Aquino e, de acordo com Vitorino (2003, p. 19), descoberta em 1772 e perdida em 1846. Armstrong (2012, p. 59) afirma que essa inscrição teria sido feita pelo menos uma ou duas décadas após a morte do poeta e seria um indicativo de que a família Júnio Juvenal continuava a ser próspera na tradução feita por Vitorino (2003, p. 20), ao nome inscrito estão associados os títulos de tribuno, duúnviro quinquenal e flâmine do imperador, cargos na sociedade romana possíveis somente a alguém que pertencesse a uma elevada posição social. A imediata associação de um Júnio Juvenal inscrito em um templo a Ceres em Aquino ao poeta satírico Juvenal advém da menção à citada região e à citada deusa na terceira sátira, pertencente ao primeiro livro da obra do poeta: "Logo, adeus, não te esqueças de mim e nas vezes/ em que devolva-te Roma pra tua, apressando-se, Aquino,/ manda que eu para a Ceres Elvina e também pra Diana/ vossa, de Cumas, regresse" $(1.3 .318-321)^{8}$. No entanto, Vitorino (2003, p. 19) aponta que não se pode considerar a inscrição uma fonte segura por, dentre alguns outros fatores, ter sido reconstituída a partir de diversas cópias e transcrições e haver divergências quanto a sua leitura. Além disso, um problema de considerar que o Juvenal inscrito no templo de Ceres seja o nosso satirista é que, conforme anteriormente mencionamos, não é possível ter certeza de que esse seja seu nome verdadeiro.

\section{O conceito de persona satírica}

Consciente da nebulosidade a respeito da vida de Juvenal e a fim de evitar que a obra juvenaliana se reduzisse a uma fonte de informações não verificáveis, William Anderson (1982) foi o pioneiro - segundo Clay (1998, p. 15) e Vasconcellos (2016, p. 23) - na aplicação do conceito de persona na análise de sátiras, especificamente as juvenalianas, embora ele não tenha sido seu inventor. Anderson (1982, p. 3) conta que ouviu, em um jantar do qual também participou, Samuel Johnson estabelecer para James Boswell uma distinção entre o que um poeta de fato pensa ou sente e aquilo que ele expressa em um

7 De nostro, facunde, tibi, Iunenalis, agello/ Saturnalicias mittimus, ecce, nuces./ Cetera lasciuis donauit poma puelis/ mentula custodis luxuriosa dei. Tradução de Fábio Paifer Carolli:"De meu campinho a ti, Juvenal eloquente,/ eis que remeto as nozes de Saturno./ As outras frutas deu às meninas lascivas/o luxurioso pau do deus guardião".

8 ergo vale nostri memor, et quotiens te/ Roma tuo refici properantem reddet Aquino, / me quoque ad Helvinam Cererem vestramque Dianam/ converte a Cumis. Tradução de Rafael Cavalcanti do Carmo. 
poema composto na primeira pessoa do singular - e este último corresponderia à persona. Segundo Anderson (1982, p. 3), esse conceito ainda não fazia parte dos estudos em literatura clássica, e, portanto, a sátira romana era uma das maiores sofredoras dessa ignorância. Seu predecessor Mack (1971, p. 192) já observara a necessidade de que os estudos sobre sátiras não se reduzissem a uma análise de suas origens ou efeitos, mas que as reconhecessem enquanto um artifício.

Antes da popularização do conceito de persona por meio do trabalho de Anderson, uma importante referência dentro dos estudos juvenalianos era o pesquisador Gilbert Highet (1954), que trabalhava com o que Braund (2004, p. 1) posteriormente denominou de falácia biográfica: Highet compreendia as sátiras como fiéis retratos das vivências e das opiniões de Juvenal e se dedicou a recompor a vida do satirista a partir de informações extraídas dos poemas, como se estes fossem puramente confessionais. Não apenas Highet adotou essa perspectiva de leitura para estudar a obra de Juvenal, mas outros pesquisadores estudaram as obras dos outros satiristas da mesma maneira. Como um exemplo, Anderson (1982, p. 4) comenta a influência da crítica biográfica nos estudos da obra do pioneiro satirista romano, Lucílio. De acordo com o autor, pelo fato de a persona luciliana apresentar-se por meio de certa espontaneidade, afirmando a própria ausência de talento literário, os estudiosos de sua obra acabavam por tratá-la como uma fonte de informações sobre o próprio Lucílio, abrindo mão de analisá-la enquanto um trabalho poético, como fariam com Virgílio, por exemplo. Anderson sintetiza assim o que considera ser a postura ideal de um estudioso da sátira romana:

A pergunta a se fazer não é: o que podemos aprender sobre a biografia de Lucílio? A pergunta a se fazer é: o que esse enunciador, essa persona, com sua invectiva contundente, seu franco erotismo, suas anedotas afiadas e seus sérios julgamentos morais, alcança para o poema?' (ANDERSON, 1982, p. 5).

O autor ainda acrescenta que, segundo pesquisas na Alemanha e na Itália, Lucílio teria sido comprovadamente um poeta sofisticado, mais alexandrino que muitos de seu tempo, ainda que a voz em seus poemas se apresentasse como descuidada e pouco talentosa (ANDERSON, 1982, p.5).

Anderson (1982, p. 6-7) apresenta críticas tão contundentes aos estudiosos de Pérsio - os quais, em sua opinião, acreditaram na falta de talento que a persona pérsica anuncia - que chega a afirmar que o estudioso ideal de Pérsio (cuja postura consistiria em saber que a persona estaria seguindo uma convenção do gênero ao se dizer pouco talentosa e que, na construção do gênero satírico, existiriam objetivos fundamentalmente poéticos) ainda não aparecera nos últimos dezenove séculos ${ }^{10}$. É precisamente da dificuldade de reconhecimento da importância poética da sátira romana que Anderson parte para declarar que nossa ignorância tenha prejudicado os estudos do gênero satírico.

No caso de Horácio, como observa Anderson (1982, p. 5), houve menos erros semelhantes de análise provavelmente devido ao fato de o poeta ter, em sua obra, poemas

9 Original: The question to ask is not: What can we learn about the biography of Lucilius? The question to ask is: What does this speaker, this persona, with his wild invective, his frank eroticism, his witty anecdotes, and his serious moral judgments, accomplish for the poem?.

10 Declaração que não mais procede, haja vista que estudos recentes, ao tratarem de Pérsio, concordam com a existência de uma persona poética, como Castro (2014) e Cairolli (2016). 
diferentes tanto em metro quanto em tema, pois essa variedade serviria por si só como um alerta ao leitor de que o autor poderia assumir diferentes máscaras. Ainda é observado por Anderson (1982, p. 5) que Horácio expressa, em sua obra satírica, uma persona muito mais séria e conservadora que a persona do carpe diem, embora as sátiras horacianas tenham sido publicadas pelo menos uma década antes das Odes.

O mesmo Horácio, em sua Arte Poética (v.156-178), disserta sobre a importância da adequação, pelos poetas, do comportamento de seus personagens à idade que eles tenham: "Não se atribua a um jovem o quinhão da velhice, nem a um menino o dum adulto; a personagem manterá sempre o feitio próprio e conveniente a cada quadra da vida" ${ }^{11}$. A ausência de uma coerência cronológica na construção de personae - isto é, a construção de uma persona velha anos antes de uma persona jovem -, em confronto com a teoria estabelecida pelo próprio Horácio que trata da verossimilhança é um argumento, a nosso ver, a favor da hipótese de que o autor empírico conscientemente crie uma voz para seus poemas. Neste caso, a adequação não se referiria a personagens em terceira pessoa, mas à personalidade de cada máscara.

Anderson (1982, p. 8-9), ao se opor à tendência biografista entre críticos da obra de Juvenal, menciona o trabalho de Gilbert Highet e afirma que, apesar de discordar dos motivos e das conclusões deste último, Anderson afirma entender que Highet assim o tenha feito por gostar de Juvenal e tentar trazer uma interpretação simpática das Sátiras. A indignação juvenaliana, para Anderson, não seria mais autêntica que a ironia horaciana ou o estoicismo persiano, e ela pode ser explicada poeticamente, sem a necessidade de se recorrer ao contexto: "Não é só porque não temos nenhuma boa biografia de Juvenal que devemos permitir que nossas imaginações corram desenfreadas"12 (ANDERSON, 1982, p. 9). De acordo com esse estudioso, Juvenal escreveu poesia de maneira elaborada, controlada e artística, e sua obra exige uma análise poética cuidadosa, não devendo, portanto, ser analisada como um documento social, como o fez - debalde - quem tentou investigar as circunstâncias que teriam levado o poeta à indignação (ANDERSON, 1982, p. vii).

Vasconcellos (2016, p. 19) alinha-se à postura de criticar interpretações literárias biografistas. Esse autor discorda da tendência, por parte dessa abordagem, de acomodar a obra à visão do autor que a escreveu. Neste sentido, o crítico, por ter uma imagem específica do poeta - mesmo que advinda de estereótipos -, tentaria transformar, a qualquer custo, o texto em uma evidência que corrobore sua concepção inicial. Outro ponto observado por Vasconcellos é a tendência, especialmente por parte de filólogos - de se procurar elementos supostamente biográficos na obra, com o único intuito de se preencher lacunas sobre a vida do autor empírico (VASCONCELLOS, 2016, p. 20). Esse vício de uma leitura biografista de obras latinas, para Martins (2008, p. 191), tem como consequência uma leitura ineficiente dos textos antigos, pois transfere para as ficções as características do vivido e confunde a verossimilhança com a verdade. O maior problema da leitura biográfica, portanto, é o empobrecimento do estudo do texto, que passa a ser analisado enquanto pretexto para se chegar ao autor empírico, e não como um trabalho artístico.

Myers (2006, p. 450) afirma que, ao ler Juvenal, o estudioso deve ter consciência de que o que está expresso nos poemas é uma percepção distorcida e exagerada de sua

11 Tradução de Jaime Bruna. Original: "Ne forte seniles/mandentur iuueni partes pueroque uiriles;/ semper in adiunctis aeuoque morabitur aptis" (Hor., Ars P., 176-168).

12 Original: Merely that we lack any good biography of Juvenal does not mean that we should allow our imaginations free rein. 
sociedade, e, portanto, a obra não deve ser lida, de maneira alguma, como uma descrição objetiva da realidade do poeta. Assim, acreditamos que o leitor deve abordar a obra com uma postura de saudável desconfiança em relação às afirmações que ali existam tanto sobre o próprio Juvenal quanto sobre seus contemporâneos e sua sociedade em geral, haja vista que existem fatores envolvidos na produção de um texto poético, como métrica e adequação ao gênero, que podem se sobrepor a uma representação verídica do real.

Embora a abordagem biográfica seja considerada por Susanna Braund (2004, p. 1) superada pelo conceito de persona poética, ainda resta dissonância entre os estudiosos de Juvenal. Concordam com a pesquisadora os estudiosos Vasconcellos (2016, p. 25-26), para quem a expressiva maioria dos autores distingue a voz autoral da voz construída no texto, e Hansen (2011, p. 145), que discorda que as sátiras sejam representação da realidade ou desabafo de seu autor. No entanto, encontramos dissonância em um trabalho relativamente recente: Tennant (1999) contesta a separação de autor e persona. Para esse pesquisador, os textos espelham a perspectiva do próprio autor (TENNANT, 1999, p. 5). Ainda, ele critica a teoria da persona por acreditar que sua aplicação desvie a atenção, por parte do leitor, da coesão e da consistência presentes na obra juvenaliana (TENNANT, 1999, p. 5-6).

Tennant $(1999$, p. 7) defende a leitura biográfica a partir dos seguintes argumentos: a) é necessário haver uma distinção entre gêneros cujos autores fazem afirmações, implícitas ou explícitas, sobre a própria personalidade - como seria o caso da sátira - e gêneros cujos autores não devem ser mais do que um nome na página, ou, ainda, permanecerem desconhecidos; b) as Sátiras foram lidas por e para um público que frequentemente conhecia pessoalmente os autores, portanto seria perceptível a inconsistência entre o poeta $\mathrm{e}$ o texto, e c) é pouco razoável partir do princípio de que as supostas contradições da obra de Juvenal são melhor explicadas segundo a teoria de que o enunciador dos textos é uma voz fabricada do que considerar que elas são simplesmente inerentes ao próprio poeta.

Prosseguindo em sua argumentação, Tennant (1999, p. 13) apresenta sua desconfiança diante da hipótese de que o público romano consumisse as sátiras de modo tão sóbrio e racional para conseguir fazer uma distinção entre a voz dos textos e as opiniões de quem as escrevera. A sátira, para Tennant (1999, p. 15), tem como característica estabelecer uma conexão entre o satirista e seu público através do humor e por meio de temas que sejam de interesse da audiência. Logo, seria paradoxal presumir que existisse uma persona artificialmente construída, já que, para uma boa relação entre o satirista e seus leitores, seria necessário que houvesse, nos últimos, um entendimento de que os textos não tratavam de mera ficção (TENNANT, 1999, p. 15).

Clay (1998, p. 9-10) afirma que mesmo uma pesquisa superficial pode comprovar que os antigos liam poesia como uma autobiografia, portanto é paradoxal que os antigos pareçam, para a atualidade, românticos por entenderem a poesia como uma expressão subjetiva do poeta. Segundo esse mesmo autor, esse tipo de leitura era muito comum na poesia elegíaca, que se utilizava da primeira pessoa, mas podia também aplicar-se a outros textos hexamétricos em primeira pessoa, como é o caso dos satiristas. Vasconcellos (2016, p. 5455) discute a questão a partir dos seguintes versos de Catulo 16, em sua tradução: "Pois casto deve ser o pio poeta/ Ele próprio, os versinhos não é preciso ${ }^{13}$ ". Para o pesquisador, a distinção entre o poeta e seus versos, neste texto, é um reconhecimento de que não existe a obrigação, por parte do escritor, de que sua voz poética se corresponda com a sua

13 Original: Nam castum esse decet pium poetam/ ipsum, versiculos nihil necesse est. 
voz pessoal. Esse poema catuliano é, para Vasconcellos (2016, p. 82-83), tanto a prova de que a leitura feita na Antiguidade era biografista, quanto um germe da noção de persona utilizada modernamente, já que o poeta teria reivindicado a distinção entre o ethos de sua poesia e seu ethos biográfico. $\quad$ Faz-se necessário, no entanto, pontuar que o conceito de persona deve ser trabalhado tomando-se alguns cuidados. Harrington (2009, p. 17), ao mesmo tempo em que reforça a impossibilidade de que a persona seja uma representação fidedigna do poeta enquanto autor empírico, discute o problema de concebê-la como uma máscara que se afasta da verdadeira personalidade de seu criador. Semelhante observação é feita por Vasconcellos (2016, p. 26-30), para quem deve-se evitar a redução desse "eu poético" a uma mera máscara fictícia sem problematizá-la, pois tratar a persona como uma entidade completamente dissociada da vivência do poeta é incorrer em um excesso tão prejudicial quanto o de partir do princípio de que persona e poeta são intrínsecos. Concordamos com o parecer geral de Vasconcellos (2016, p. 37) sobre o tópico:

\begin{abstract}
Assim, não nos parece totalmente adequado tratar da questão simplesmente como verdade/ ficção; ars/vita: mesmo que possamos ter certeza de que o poeta narra fatos de sua vida ou expressa sentimentos que possui de fato, no construir-se da obra literária tudo será passado pelo crivo das convenções, da tradição, do social. Há momentos na literatura ou no percurso de determinado poeta em que se busca um efeito maior de real, de confissão, de ausência de artifício, mas esses efeitos resultarão da construção retórica do texto, condicionamento inescapável. Todo texto cria um ethos para seu enunciador; assim, a impressão de sinceridade sempre será um efeito textual. (VASCONCELLOS, 2016, p. 37).
\end{abstract}

Freudenburg (2006, p. 28), ao posicionar-se em relação à questão da complexidade da aplicação do conceito de persona na análise dos textos satíricos, afirma que os estudos clássicos devem manter em consideração que existe um lado político na sátira, portanto o estudo dos efeitos textuais presentes no gênero não deve concebê-los apenas como mecanicamente produzidos, mas tratar de como esses efeitos teriam atuado em seu momento - altamente político - de produção. Freudenburg (2006, p. 29) não considera vantajoso que se insista que Juvenal tenha sido uma persona, como se existisse a possibilidade de ele ser outra coisa, ou que sua performance fosse entretenimento desprovido de ofensas ou significado político, afinal o ato da sátira acontece na recepção, não antes, e ao pensarmos na performance devemos levar em consideração, além do autor, também a plateia que consumia os textos.

Embora seja inegável a expressividade da aplicação do conceito de persona poética nas análises modernas de textos antigos, percebemos, a partir das ponderações trazidas acima, que essa questão não está solucionada. Os versos de Catulo podem ser tomados, de fato, como um argumento que corrobora a cisão entre poeta e homem, no entanto permanece a lacuna, nos textos teóricos antigos, da ausência de menções à construção dessa persona poética. Como recomendou Vasconcellos, o que podemos fazer diante desse impasse é procurar nesses textos argumentos que possam fortalecer a razoabilidade da aplicação do conceito.

$\mathrm{Na}$ Arte poética de Horácio, que já mencionamos, encontramos, em linhas gerais, uma reflexão sobre o trabalho do poeta, a importância da verossimilhança e o reforço de que o dom natural e o esforço são igualmente importantes na tarefa do escritor por serem interdependentes. Se a autoproclamada falta de habilidade composicional de Pérsio não se comprova 
pelos estudiosos de sua obra, como observamos anteriormente, não há por que acreditar na sinceridade juvenaliana ao afirmar que compõe por indignação, apesar da ausência do dom.

Além disso, deve-se considerar que os textos de Juvenal, além de serem compostos em um metro específico do gênero satírico - hexâmetro dactílico -, também aludem a Lucílio, considerado inventor da sátira. Um texto, portanto, que respeita a métrica do gênero em que se insere e explicita sua própria genealogia não pode ser interpretado como simples rompante espontâneo simplesmente por apresentar uma linguagem agressiva. Se nas Sátiras juvenalianas delineia-se um personagem que se propõe a acusar os vícios de seus contemporâneos, o exagero em sua expressão é perfeitamente coerente e atende à necessidade de verossimilhança apontada por Horácio. Embora concordemos com a correspondência, em alguma medida, entre poeta e homem, mas não possamos determinar, com as ferramentas que atualmente possuímos, qual seja exatamente essa medida, defendemos que esse personagem indignado é uma criação artística, feita com objetivos poéticos específicos e, portanto, necessariamente trabalhada por seu autor.

\section{A mudança de tom em Juvenal}

Anderson (1982, p. 198) comenta que há uma reconhecida desproporção ou falta de unidade da poesia juvenaliana, e a sua escolha por temas não muito complexos fez com que essa fosse tradicionalmente associada às controversiae ${ }^{14}$ retóricas ou às diatribes, no entanto ele não acredita que seja esse o caso. Anderson (1982, p. 198) é defensor de que novas formas de abordagem da obra juvenaliana sejam exploradas, para que nenhum dos aspectos anteriores constitua um defeito, mas sejam tomados como qualidades positivas da obra de Juvenal, e afirma:

Eu me refiro [ao sugerir que aspectos tidos como defeitos passem a ser vistos de forma positiva] ao valor das palavras temáticas e das metáforas, ao significado de contrastes repetidos, e à importância semântica de alusões e cenas dramáticas; eu também me refiro a uma perceptível técnica de exposição gradual do tema, e um procedimento regular de introdução e conclusão. Quando considerarmos a variedade de técnicas empregadas por Juvenal, todas contribuindo para um esquema estrutural peculiar, nós mudaremos nossa opinião sobre seu trabalho, ou pelo menos nos protegeremos de vê-lo com os pré-conceitos do estudante de Horácio ou Virgílio ${ }^{15}$. (ANDERSON, 1982, p. 198)

Pensar nessa dita falta de unidade da obra juvenaliana implica discutir uma questão muito importante dentro dos estudos sobre as sátiras de Juvenal, pela ausência de consenso por parte dos pesquisadores sobre o assunto: a mudança de tom ao longo dos poemas.

14 As controversiae eram exercícios de declamação em que o aluno deveria defender algum lado em um caso judicial imaginário (COSTRINO, 2010, p. 14-15). Há uma compilação em 10 livros de Controversiae do retor Sêneca, o Velho.

15 Original: I refer to the value from thematic words and metaphors, to the significance of repeated contrasts, and the semantic importance of allusions and dramatic scenes; I refer also to an observable technique of gradually exposing the theme, and a regular procedure of introduction and conclusion. When we consider the variety of techniques employed by Juvenal, all contributing to his particular structural scheme, we may well reverse our opinion of his work, or at least guard ourselves from viewing him with the preconceptions of the student of Horace or Vergil. 
A primeira sátira de Juvenal se inicia com o satirista se questionando se sempre deverá estar na posição de apenas ouvinte - "Semper ego auditor tantum?" (Juv., 1.1.1) -, listando críticas à produção de seus contemporâneos - poemas épicos que são distantes da realidade cotidiana de Roma - e ao comportamento de indivíduos da sociedade romana em geral. Essa mordacidade se mantém em constância nas primeiras seis sátiras, que constituem seus dois primeiros livros, nos quais abundam ataques a diversos aspectos de seus contemporâneos. Esse mesmo satirista, embora mantenha um posicionamento rígido diante dessas questões, passa, nas sátiras posteriores, a intercalar seus ataques com momentos mais contidos e meditativos.

Por exemplo, observemos um trecho da primeira sátira de sua obra: "E quando houve mais copiosas de vício abundâncias? E quando/ mais da avareza estenderam-se as garras? Aos dados, outrora,/ quando tamanhos impulsos?" ("Et quando uberior vitiorum copia? Quando/ maior avaritiae patuit sinus? Alea quando/ hos animos?”, Juv., 1.1.87-89). O satirista, por meio do exagero e da ênfase, ao afirmar que o momento em que vive representa o ponto mais baixo do declínio da sociedade, demonstra insatisfação com o comportamento de muitos de seus contemporâneos, os quais são viciosos, avaros, impulsivos.

Especialmente nas seis primeiras sátiras, que constituem os Livros 1 e 2, essa invectiva é constante e, embora se torne menos frequente nas sátiras subsequentes, não desaparece. Um outro exemplo que podemos trazer do que a crítica considera a fase branda de Juvenal é o seguinte excerto da Sátira 13: "Mas a vingança é um bem que me apraz mais que a vida em si mesma!"/ Isso é o que dizem os tolos, dos quais as paixões por um nada/ sempre verás conflagradas, por causas que mesmo inexistem;/ seja quão ínfima for a ocasião já lhes basta pra raiva." ("“at vindicta bonum vita iucundius ipsa.'/ nempe hoc indocti, quorum praecordia nullis/ interdum aut levibus videas flagrantia causis;/ quantulacumque adeo est occasio sufficit irae", Juv., 13.180-184).

Aqui o enunciador consola o interlocutor, Calvino, que se encontra incomodado por não receber o pagamento de um empréstimo que fez a um amigo. Ao longo da sátira, o satirista tenta acalmá-lo, abordando sua situação a partir da perspectiva de que é possível ser vítima de crimes muito piores, e a raiva é inútil. Vemos, portanto, que o satirista que, na primeira sátira de sua obra, afirma que a indignação compõe seus versos, se propõe, na décima terceira, a aconselhar um interlocutor acerca da inocuidade da raiva e da exaltação. A ocorrência dessa condenação da ira e, de modo geral, o surgimento de trechos tais como esse, em que a persona não ataca ninguém, mas aconselha ou reflete sobre alguma questão, foi o ponto de partida da abundante discussão que existe entre os críticos de Juvenal acerca da mudança de tom na obra.

Segundo a perspectiva de Highet (1954, p. 4), que considera que Juvenal tenha começado a escrever por volta dos 45 anos de idade - devido ao fato de já nos poemas iniciais existir uma abordagem da juventude como algo que está no passado - e, observando o modo negativo com que a velhice é retratada nas sátiras posteriores - em sua fraqueza e feiúra -, a escrita da obra provavelmente terminou próximo à época de morte do poeta. Segundo esta suposição, portanto, a mudança de tom que o crítico observa das seis primeiras sátiras em relação às últimas, com o abrandamento da indignação e a linguagem menos agressiva, explicar-se-ia a partir do envelhecimento do próprio poeta e, por conseguinte, da adoção de uma postura mais resignada e mais distante da vida.

Anderson (1982) entende a obra juvenaliana em dois momentos, no entanto o aspecto variável seria não a perspectiva do autor, como afirma Highet, mas a persona satírica. 
Anderson (1982, p. 295) percebe uma clara distinção entre dois momentos da obra do satirista: nas sátiras 1-6, há o satírico indignado, anunciado por Juvenal desde a primeira sátira do Livro 1 e retomado na Sátira 6 ou Livro 2; e, nas sátiras 10-16, há o satírico que ri, que condenaria a indignação das sátiras anteriores. Os poemas 7-9, por serem considerados o momento de transição de uma persona para a outra, não recebem muita atenção. Anderson (1982, p. 315-339) analisa os pontos de aproximação entre as sátiras finais de Juvenal e as obras De ira e De tranquilitate anima, do filósofo Sêneca, de modo a defender que este tenha sido uma grande influência para a mudança de tom juvenaliana. Sêneca concebe a ira como irracional - portanto condenável - e inócua. Para Anderson (1982, p. 339), Juvenal teria, a partir dos textos de Sêneca, se identificado com aquilo de que trata o filósofo e optado por criar um satirista que se conformasse com essas ideias.

Vitorino (2003, p. 98), de modo aproximado ao de Anderson, também divide a sátira juvenaliana em dois momentos: um primeiro, declamatório, marcado pela indignação, e um segundo, de tranquilidade e meditação. No entanto, Vitorino (2003, p. 102) se posiciona em uma espécie de meio-termo nessa questão: a autora se opõe a uma demarcação que diferencie as personae de modo tão claro, já que essa mudança de tom não é, em momento algum, anunciada pelo satirista, e nem ocorre de forma linear.

A hipótese mais radical sobre o assunto, de acordo com Vitorino (2003, p. 98), é a proposta por Ribbeck, segundo o qual as últimas cinco sátiras da obra de Juvenal não teriam sido compostas pelo mesmo poeta que escreveu as primeiras. Sobre essa bipartição da obra, Carmo (2013, p. 62) comenta que os critérios utilizados por Ribbeck para determinar a legitimidade da autoria das sátiras foram confusos e pouco conclusivos. Segundo essa organização, as nove primeiras sátiras e a décima primeira teriam sido realmente escritas por Juvenal, enquanto a décima, a décima segunda e as quatro subsequentes seriam de autoria de um declamador que conseguira fazer as próprias composições passarem como se fossem juvenalianas.

Vitorino (2003, p. 101) observa ainda que as diferentes opiniões de autores sobre a questão geralmente provêm de uma leitura puramente biográfica ou psicológica. Tal ressalva nos parece prudente, pois, como bem observa Carmo (2014, p. 16), a suposta verdade de uma obra literária se encontra apenas na mente de seu autor empírico - de modo não estático, pois o contato com a audiência pode desestabilizá-la -, sendo, portanto, inacessível a nós. Supor que a mudança de tom em uma obra se deva a fatores pessoais externos ao texto é adentrar um universo especulativo de difícil comprovação. No caso de Juvenal, essa questão se torna ainda mais complexa diante da ausência de dados biográficos legítimos. Se lidamos com um corpus de textos que apresenta uma notável variação de temas e tons, mas não nos é possível acessar de fato a pessoa responsável pelas composições, parece-nos irrelevante tentar determinar o motivo dessa mudança, pois qualquer hipótese que surja a respeito do que possa ter acontecido jamais poderá ser comprovada. Antes é mais profícuo para o estudioso observar de que forma tais variações contribuem para a constituição e a complexidade da obra.

Sobre este tema, Vitorino (2003, p. 101-102) alerta para o simplismo de concordar com Anderson, segundo quem, como trouxemos anteriormente, Juvenal foi influenciado por Sêneca, dado que o poeta escreveu por bastante tempo e provavelmente recebeu influência de outros autores que não são citados como uma influência tão relevante quanto Sêneca. Além disso, como observamos, a autora propõe que esses dois momentos da obra não sejam vistos de forma tão linear e demarcada, já que existem, nas últimas sátiras, indí- 
cios da indignatio das primeiras, bem como seria possível perceber traços do satírico que ri já nos livros iniciais de sua obra. De modo geral, nessa perspectiva, não se deve compreender a mudança de tom como um processo definitivo, pois sua postura pode oscilar.

Ainda segundo Vitorino (2003, p. 101), a ausência de uma consistência dessa mudança de postura se deve às próprias características do gênero satírico, que permite que o poeta explore diferentes formas de se expressar. Desse modo, na mesma medida em que devemos reconhecer que existe uma complexidade na personalidade desse satirista, não podemos ver suas mudanças de forma simplista, como mero produto de mudanças externas ao texto - biográficas ou históricas - sem intencionalidade artística. A autora conclui pontuando que a mudança de tom não é declarada ou definida por Juvenal, logo é necessário que se tenha cuidado ao discutir a questão para que não se caia em uma busca por evidências que, no fim das contas, não são de qualquer forma produtivas para compreender a magnitude da obra ou a complexa personalidade do poeta (VITORINO, 2003, p. 102-103).

Peter Tennant (1999) e James Harrington (2009) trazem um contraponto interessante à discussão acerca da mudança de tom, que, de certa maneira dialoga com a moderação acima proposta por Vitorino, em que ambos os autores também assumem um posicionamento intermediário na questão. Ainda que esses autores não neguem que seja observável uma certa variação no tom, eles não o consideram relevante a ponto de, por exemplo, seccionar a obra juvenaliana em dois momentos, um de indignação e o outro de abrandamento. Um aspecto que os discerne, porém, é a admissão da existência da persona poética, aceita por Harrington (2009) e negada por Tennant (1999).

Tennant (1999) não reconhece, como observamos, que exista na obra a falta de unidade comentada por Anderson (1982). Para Tennant, a mudança de tom ao longo das sátiras significa apenas que o poeta tenha adotado uma técnica satírica menos agressiva de modo a adequar o tom aos temas que aborda em suas sátiras posteriores. Na perspectiva de Tennant, o fato de ser possível perceber, na última sátira, ecos do Juvenal ácido da primeira, comprova que não existe uma persona criada e alterada ao longo da obra, mas que o poeta tenha sido genuíno em sua própria personalidade.

Tennant $(1999$, p. 4), portanto, se opõe à teoria da persona poética, por acreditar que esta distancia o poeta do público. Esse autor defende que a ausência de dados biográficos empíricos sobre Juvenal não deve significar que seja impossível acessar sua verdadeira personalidade e atitudes. $\mathrm{O}$ autor afirma que existe uma personalidade consistente ao longo de toda a obra e que a assunção de diferentes personae na obra encobriria essa coerência (TENNANT, 1999, p. 5). No que diz respeito à mudança de tom ao longo da obra, Tennant $(1999$, p. 6) é partidário de que, ainda que ela ocorra para se adaptar ao tema abordado, a ira e a indignatio juvenalianas se mantêm como constituintes de sua personalidade, e, se não aparecem de forma tão explícita em alguns contextos em que a invectiva não pareça adequada, elas permanecem latentes.

Harrington $(2009$, p. 3), também defensor da unidade e da coerência das sátiras, observa que na concepção que fragmenta a obra juvenaliana subjaz uma lógica segundo a qual é necessário existir uma postura filosófica coerente e una por trás do texto. Desta forma, como observa o autor, se o enunciador de um livro não se mantém correspondente ao de outro, a crítica tende a compreender um dos dois como uma caricatura ou uma imperfeição. $\mathrm{O}$ argumento de Harrington diante da pluralidade de expressões que a obra de Juvenal assume é que havia em Roma - e o autor pontua que não se trata de uma exclusi- 
vidade romana, mas de algo esperado na constituição de qualquer sociedade - uma grande diversidade de pensamentos e posicionamentos, o que coloca os autores numa posição de constante disputa, como se suas perspectivas concorressem umas com as outras. Para esse autor (HARRINGTON, 2009, p. 3), a sátira romana e, especificamente, os textos de Juvenal, são intencionalmente inseridos nesse certame de significados.

O gênero satírico romano, segundo Harrington $(2009$, p. 4), humorístico e performático, necessariamente deve partir de um determinado ponto de vista e de uma postura moralista definida, para que não se esvazie de significado. Para o autor, não há surpresa no fato de Juvenal ter impresso em sua obra diferentes temas sob diferentes tons; pelo contrário, notável seria se o autor tivesse se mantido tão regular ao longo dos cinco livros que constituem sua obra. Ele também afirma que a temática e o tom sejam correlatos, e, desta forma, seria autoexplicativo que a mudança de tema signifique a mudança de tom (HARRINGTON, 2009, p. 6).

Embora Tennant e Harrington também discordem quanto à existência da persona, a divergência entre ambos é mais sutil do que a existente entre Anderson e Highet. Tennant (1999, p. 6-7) se opõe a uma reconstrução biográfica especulativa a partir dos textos na mesma medida em que é desfavorável à negação de qualquer correspondência entre os poemas juvenalianos e a verdadeira personalidade de seu autor. Para o estudioso, considerar a suposição de que Juvenal estivesse escrevendo por si mesmo explicaria as aparentes contradições e inconsistências que permeiam sua obra, tendo em vista que ela tenha sido escrita, em sua totalidade, ao longo de vinte anos e, ainda que existam naturais variações, há uma mesma personalidade que se mantém nos cinco livros. Percebemos, portanto, que o argumento de Tennant para a negação da persona se baseia no entendimento de que esta seria uma completa dissociação de seu autor empírico, extremismo que Harrington também problematiza.

Deve-se pensar que Juvenal, ciente da produção literária de seu tempo, do gênero que escolheu para escrever e, ainda, cônscio da audiência por quem seus poemas seriam consumidos, fez escolhas quanto aos temas que abordaria e à forma como os abordaria. Há, nesta lógica, uma concepção da obra juvenaliana com a qual somos concordes: se é possível justificar os critérios que ditaram a composição de Juvenal, eles provavelmente se relacionarão com seus objetivos poéticos - os quais não somos capazes de determinar - enquanto um escritor de sátira e enquanto um participante da produção literária de seu período.

Esses objetivos, portanto, compõem-se de escolhas por parte do poeta acerca de seu conteúdo e da forma como os aborda, o que nos leva de volta à questão do tom. Tennant (1999, p. 303) o atribui a uma evolução natural do próprio Juvenal, além de defender que o tema das sátiras esteja correlacionado com o tom em que elas serão apresentadas - deste modo, alguns temas exigiriam um tom mais agressivo ao passo que outros seriam melhor expressos em uma tonalidade mais conformada e segundo um ponto de vista mais analítico.

Considerando os autores que discutimos neste capítulo, percebemos a abundância de perspectivas a partir dos quais é possível compreender a obra de Juvenal. Para Highet (1954), o poeta escreve a partir de suas próprias impressões e, portanto, representa a si mesmo e a suas vivências em sua obra, e a mudança de tom da obra se deveria ao amadurecimento do próprio poeta, à medida que envelhecesse. Anderson (1982) propõe o conceito de persona, uma máscara criada pelo poeta que não corresponderia ao autor empírico e descarta a possibilidade de se tentar reconstruir quem tenha sido Juvenal a partir da leitura de sua obra, além de considerar que a mudança de tom tenha ocorrido conforme 
o poeta foi influenciado por outros autores ao longo de seu tempo de composição. Tennant (1999), por entender o conceito de persona como uma forma de afastar o público da obra, opõe-se à aplicação desse conceito e defende a possibilidade de se acessar o autor empírico por meio do estudo de seus poemas, além de se opor a uma concepção fragmentada da obra juvenaliana - e, inclusive, argumentar que a acepção da existência da persona tenha contribuído para essa visão. Harrington (2009), percebendo o risco de se cometerem distorções interpretativas em ambas as abordagens - biográfica e ficcionalista, com aplicação do conceito de persona - opta por adaptar essa última, compreendendo-a como um recurso que faz parte das composições, mas que não se relaciona tanto com o poeta, e sim com o campo literário e com o público, além de defender que a obra juvenaliana é coerente e una, argumentando que compreendê-la como fragmentada é supor que a congruência só exista a partir de uma postura inalterada - uma expectativa irrealista. Vitorino (2003), adepta da aplicação do conceito de persona devido à inconsistência de se fazer a leitura biográfica da obra de um autor sobre cuja vida não existe nenhum dado empírico, entende que seus poemas dividem-se em dois momentos, o primeiro, de indignação, e um segundo, de meditação.

A forma como nos posicionamos nessa discussão, conforme demos indicativos ao longo do texto, é a concordância com a aplicação do conceito de persona, como propôs Anderson (1982); no entanto, a nosso ver, não existe mais de uma. Entender que exista uma fragmentação da obra juvenaliana é considerar que o tom - e sua oscilação/mudança - desempenhe um papel essencial na obra. No entanto, advogamos pela priorização dos temas e da postura do satirista em detrimento do tom que ele utiliza. Se é possível perceber uma familiaridade nas sátiras finais em comparação com as iniciais, no que diz respeito aos tópicos que a persona poética aborda e à forma como ela se posiciona diante dos assuntos de que trata, então não há necessidade de fragmentar essas assertivas por estarem colocadas de uma forma diferente.

No primeiro livro, o satirista é categórico ao afirmar que a riqueza se sobrepõe à infâmia - no sentido de que é possível se safar de qualquer infração ou desonra quando se tem dinheiro - e que a única forma de ascender socialmente é por meio do crime: "Qual é o peso, salvando-se a grana, da infâmia?" (Quid enim salvis infamia nummis?", Juv., 1.1.48); ainda:

Ousa alguma coisa das breves Giouras, do cárcere digna, caso ser algo tu almejes; a honra é louvada e perece.

Devem-se aos crimes as hortas, os altos ofícios, as mesas, a prataria antiquária e na alça do cântaro o bode

Aude aliquid brevibus Gyaris et carcere dignum, si vis esse aliquid. Probitas laudatur et alget; criminibus debent hortos, praetoria, mensas, argentum vetus et stantem extra pocula caprum" (Juv., 1.1.73-75).

Já na primeira sátira do seu quarto livro, ele discorre sobre a ausência de racionalidade nos medos e desejos humanos e comenta que muitas pessoas sufocam pelo excesso de dinheiro e preocupação com a própria fortuna: "O que tememos ou desejamos segundo a razão?" (quid enim ratione timemus/ aut cupimus?, Juv., 10.5-6); também: "Mas, para 
muitos, a preocupação excessiva com os bens guardados/ os estrangula, e seu patrimônio supera o censo,/ assim como a baleia britânica é maior que o golfinho" ${ }^{16 "}$ " "sed pluris nimia congesta pecunia cura/ strangulat et cunctas exuperans patrimonia censu/ quanto delphinis ballaena Britannica maior", Juv., 10.12-15).

O posicionamento do satirista é o mesmo em ambas as situações: a persona demonstra sua discordância acerca do acúmulo excessivo de bens. No entanto, a forma como ela traz esse posicionamento é diferente. Na primeira sátira, o enunciador traz uma opinião enfática sobre o tema, estabelecendo uma relação intrínseca entre dinheiro e crime - para ser rico, é necessário ser criminoso, no entanto, sendo rico, não se sofre punição por nenhum crime. Já na décima sátira, existe a ponderação sobre a ausência de racionalidade naquilo que os humanos ambicionam e temem para, poucos versos adiante, a persona afirmar que algumas pessoas vivem angustiadas por se preocupar em excesso com sua fortuna, que é maior do que precisariam ter. Nesta segunda situação, os gananciosos não são descritos como criminosos, mas como irracionais. $\mathrm{O}$ fato de o satirista conseguir se afastar de seu objeto de crítica a ponto de não tratá-lo de forma inflamada, mas abordá-lo de forma mais meditativa, não significa que ele tenha mudado sua opinião. Em ambos os momentos, o que existe é uma crítica ao acúmulo excessivo de bens, e essa permanência de posicionamento ao longo da obra não deve ser ofuscada em função da oscilação de tom.

Este exemplo, inclusive, refuta a hipótese levantada por Tennant (1999) e Harrington (2009) quando se opõem a uma perspectiva fragmentária da obra: ambos argumentam que o tom mude de acordo com o tema. Acima, observamos a persona se posicionando de duas formas diferentes sobre uma mesma questão: ser rico. Há vários outros exemplos ao longo da obra, como o que trazemos a seguir. "Nada haverá de pior que a essas nossas maneiras acresça/ a posteridade, e o mesmo fazer e almejar vão seus filhos" ("Nil erit ulterius quod nostris moribus addat/ posteritas, eadem facient cupientque minores", Juv., 1.147-148). Aqui o satirista concebe os indivíduos ao seu redor como tão viciosos que a sociedade estaria fadada a um declínio, com a hereditariedade e, por conseguinte, a perpetuação desses hábitos. Na sátira 13, em seu último livro, a persona afirma: "Na nona era pior tem-se agido do que nos do ferro/ tempos, e aos crimes de agora não pode encontrar nenhum nome/ a natureza ela mesma: lhe falta um metal mais rasteiro" ("nona aetas agitur peioraque saecula ferri/ temporibus, quorum sceleri non invenit ipsa/ nomen et a nullo posuit natura metallo”, Juv., 5.13.28-30).

O seu tema, novamente, é o mesmo: a decadência de seu tempo. No entanto, sua forma de abordagem se diferencia da anterior. Aqui, o satirista se posiciona de forma mais ponderada, e, novamente, mais afastada de seu objeto de censura. Também aqui vemos uma opinião que se mantém ao longo da obra - pois ela surge no primeiro livro e é retomada no último -, e, portanto, invalida a concepção fragmentária dos textos.

\section{Considerações finais}

Como a questão da persona e a mudança de tom são aspectos intrínsecos entre si para a crítica, que considera que um seja determinado pelo outro, pensamos ser pertinente propor um questionamento diante das hipóteses que aqui observamos acerca do tom. Não

16 Tradução nossa. 
discordamos de que seja notável que o satirista adote um novo tom em sua obra, no entanto sua agressividade inicial não se dissipa completamente para dar lugar a momentos meditativos, o que nos inclina a pensar que esse novo tom antes conviva com o antigo do que o substitua. Como observou Tennant (1999), na última sátira da obra de Juvenal é possível reconhecer a indignatio que se pensava restrita aos seus primeiros livros. Caso essa mudança de tom fosse um processo diretamente ligado ao amadurecimento de Juvenal, ou mesmo se sua justificativa se pautasse simplesmente na aquisição de novas influências, então o que faria com que o poeta, em sua última sátira, retornasse ao "amadorismo" que o teria levado a optar pela indignatio como forma de expressão no início de sua obra?

À guisa de conclusão de nosso posicionamento sobre a questão, argumentamos que, para nós, essa perceptível familiaridade na leitura das sátiras finais - no sentido de constatar a permanência de um mesmo posicionamento exibido desde o início da obra - basta para que cheguemos à conclusão de que não existe uma transição da persona, mas diferentes aspectos de sua constituição que emergem à medida que prosseguimos com a leitura dos textos. A mudança na forma como o satirista passa a abordar os temas não implica uma discordância da postura que anteriormente tenha exibido - e, ainda que o significasse, a nosso ver essa seria uma questão passível de discussão, considerando as observações de Harrington acerca da exigência de uma uniformidade, por parte do autor, para que a crítica considere sua obra coerente e una. Discordamos da relação entre tom e tema por acreditarmos ser uma inverdade, como demonstramos nos exemplos acima, e defendemos a unidade da obra, a qual seria constituída por uma única persona, priorizando-se a recorrência de temas em detrimento da suposta mudança de tom.

\section{Referências}

ANDERSON, William. Essays on Roman Satire. Princeton: Princeton University, 1982. ARMSTRONG, David. Juvenalis Eques: A Dissident Voice From The Lower Tier of the Roman Elite. In: BRAUND, Susanna; OSGOOD, Josiah. A Companion to Persius and Juvenal. Malden: Blackwell, 2012. p. 59-78.

BRAUND, Susanna. Introduction. In: JUVENAL; PERSIUS. Juvenal and Persius. Edited and translated by Susanna Morton Braund. Cambridge: Harvard University, 2004. p. $1-39$.

CAIROLLI, Fábio Paifer. Pérsio, Sátira 4: uma proposta de tradução. Estudos Linguísticos e Literários, Salvador, n. 55, NÚM. ESPECIAL, p. 386-397, 2016. Disponível em: https://portalseer.ufba.br/index.php/estudos. Acesso em: 21 maio 2020.

CARMO, Rafael Cavalcanti do. As manifestações do cômico nas "saturae” de Juvenal. 2014. 142 f. Dissertação (Mestrado em Letras) - Programa de Pós-Graduação em Letras, Universidade Federal do Espírito Santo, Vitória, 2014.

CASTRO, Marihá Barbosa e. O programa satírico de Pérsio frente à tradição. 2015. 146 f. Dissertação (Mestrado) - Programa de Pós-graduação em Letras, Universidade Federal do Espírito Santo, Vitória, 2015.

CITRONI, Mario. "Musa pedestre”. In: CAVALLO, Guglielmo; FEDELI, Paolo; GIARDINA, Andrea (Org.). O espaço literário da Roma antiga. Tradução de Daniel Peluci Carrara e Fernanda Messeder Muora. Belo Horizonte: Tessitura 2010. p. 329-360. CLAY, Diskin. The Theory of the Literary Persona. Materiali e Discussioni Per L'analisi Dei Testi Classici, Roma, v. 40, p. 9-40, 1998. 
CORDEIRO, Iana Lima. A constituição da persona satírica na obra de Juvenal. 2019. 127 f. Dissertação (Mestrado) - Programa de Pós-graduação em Letras, Universidade Federal do Espírito Santo, Vitória, 2019.

COSTRINO, Artur. A lição dos declamadores: Sêneca, o retór, e suas as suasórias. 2010. 126 f. Dissertação (Mestrado em Letras) - Programa de Pós-graduação em Letras Clássicas, Universidade de São Paulo, São Paulo, 2010.

FREUDENBURG, Kirk. Introduction: Roman Satire. In: FREUDENBURG, Kirk (Ed.). The Cambridge Companion to Roman Satire. Cambridge: Cambridge University, 2006. p. 1-30.

HANSEN, João Adolfo. Anatomia da sátira. In: VIEIRA, Brunno; THAMOS, Márcio (Org.). Permanência Clássica: visões contemporâneas da Antiguidade greco-romana. São Paulo: Escrituras, 2011. p. 145-169.

HARRINGTON, James Matthew. Mens Sana: Authorized Emotions and the Construction of Identity and Deviance in the Saturae of Juvenal. 2009. 239 f. Tese (Doutorado) - Philosophy, Classical Studies, University Of Michigan, Ann Arbor, 2009.

HIGHET, Juvenal the Satirist: a Study. New York: Oxford University, 1954. HORÁCIO. Arte poética. In: ARISTÓTELES, HORÁCIO, LONGINO. A poética clássica. Introdução de Roberto de Oliveira Brandão. Tradução de Jaime Bruna. São Paulo: Cultrix, 2014. p. 53-68.

HORÁCIO. Sátiras. Tradução de Antônio Luís Seabra. São Paulo: Edipro, 2011.

JUVENAL. Juvenal and Persius. Edited and translated by Susanna Morton Braund. Cambridge: Harvard University, 2004.

MACK, Maynard. The Muse of Satire. In: PAULSON, Ronald. Satire: Modern Essays in Criticism. Englewood Cliffs: Prentice-Hall, 1971. p. 190-201.

MARTINS, Paulo. Breve história da crítica da Literatura Latina. Classica - Revista Brasileira de Estudos Clássicos, São Paulo, v. 21, n. 2, p.189-204, 2008. Disponível em: $<$ https://revista.classica.org.br/classica/article/view/190>. Acesso em: 27 fev. 2018. MYERS, K. Sara. Imperial Poetry. In: POTTER, David S (Ed.). A Companion to the Roman Empire. Blackwell: Oxford University, 2006. p. 439-452.

TENNANT, Peter Michael Wellesley. Mask or Mirror?: A Study of Juvenal's Satire as a Reflection of Authorial Personality and Perspective. 1999. 314 f. Tese (Doutorado) - Curso de Filosofia, Universidade de Natal, Durban, 1999. Disponível em: < http://researchspace.ukzn.ac.za/handle/10413/8757>. Acesso em: 07 abr. 2018.

VASCONCELLOS, Paulo Sérgio de. Persona poética e autor empírico na poesia amorosa romana. São Paulo: Unifesp, 2016.

VITORINO, Mônica Costa. Juvenal: o satírico indignado. Belo Horizonte: UFMG, 2003.

Recebido em: 26/05/2020; Aceito em: 25/06/2020 